\title{
Pandemic Lessons
}

\author{
Stephen S. Morse, PhD (1)
}

"People ask me to predict the future, when all I want to do is prevent it."

$$
\text { -Ray Bradbury }
$$

The name of this journal, Disaster Medicine and Public Health Preparedness (DMPHP), seems especially apt for the current pandemic. When this coronavirus pandemic had just started, Dr James recognized the appropriateness of severe acute respiratory syndrome coronavirus 2/coronavirus disease (SARS-CoV-2/COVID-19) for this journal and graciously extended me an invitation to serve as Guest Editor for this subject. Little did we suspect what we had gotten ourselves into.

Since then, as the pandemic has progressed through much of the world, the outpouring of knowledge and experience has been overwhelming. The journal has received and published a wide variety of papers on the pandemic, covering the full range of subjects in the journal's title (and then some). Many recurrent questions in disaster medicine are addressed: first-hand experiences quickly adapting medical facilities and services or building new ones to handle the pandemic onslaught; new clinical findings and best practices learned from the experience; deployment and mental health of health care workers; and dealing with the simultaneous threats of more traditional disasters, like hurricanes or wildfires, while trying to prevent the spread of the virus in evacuation shelters. These are true disaster medicine experiences, although we may not often think of an infectious disease in this vein.

Public health preparedness lessons are also well represented, including (to sample just a few) screening and containment strategies; studies of the spread of the infection on cruise ships; the use of epidemiologic data and modeling to forecast the pandemic's effect; the gaps in readiness, public health response, health equity, and policy laid bare by the pandemic; and handling the conflicting communications that seem to have become inseparable from this pandemic in many places.

How did we get here? A timely and coordinated public health response could have contained the spread of the infection. How the infection was transmitted, and transmission from asymptomatic or mildly symptomatic individuals, were already clear as the virus began its trek in Asia, and we have long studied how public health could contain a respiratory virus. For well over a decade, we have wondered what the next pandemic would be, and how it would play out. The appearance of the first new coronavirus known to infect humans, SARS in 2003, virtually coincided with avian influenza, H5N1, truly alarming to many. Mathematical modelers, motivated by the concern that $\mathrm{H} 5 \mathrm{~N} 1$ had pandemic potential, showed it was possible to contain an influenza pandemic (and presumably any contagious respiratory infection) at its source, if we recognized it and acted quickly enough, essentially through public health measures, although antivirals and vaccines would be helpful. ${ }^{1,2}$ It was clearly a very challenging task, but not impossible. ${ }^{1}$ This could also be applied more locally to break chains of transmission and prevent virus spread. ${ }^{2}$ Then, the 2009 influenza pandemic came and, far from the apocalyptic event some expected, perhaps lulled us back into complacency. This may have been reinforced by the feeling that we had successfully "vanquished" SARS in 2003.

Since SARS, there have been literally dozens, if not hundreds, of exercises for authorities to confront global pandemics. One of the most recent, "Event 201," was organized by the Johns Hopkins Center for Health Security and held in New York on October 18, 2019. ${ }^{3}$ To vary the scenario, which was usually a major flu pandemic and sometimes smallpox (an especially stressful scenario), the organizers chose a fictional coronavirus that could spread by the respiratory route. The scenario was sufficiently realistic that when the actual coronavirus pandemic hit a few months later, the Center had to put a disclaimer on its website that the forecasts from the simulation exercise were fictional. ${ }^{3}$

The virus now called SARS-CoV-2, and the disease called COVID-19, first appeared in December 2019 as an unexplained pneumonia in Wuhan, China. The world and the World Health Organization first became aware of it, just as with the original SARS in 2003, from an item in ProMED-mail (Program for Monitoring Emerging Infections), a platform for disease reporting and discussion on the Internet. ${ }^{4,5}$ Advanced biotechnology allowed scientists to have the complete RNA genome of the virus about 2 weeks later, just as the virus was spreading in countries outside China. Despite an unparalleled amount of information, there was astoundingly no discernible global strategy or coordination. Our colleagues in Asia and Italy were among the first to experience the 
force of the pandemic, and the lessons they learned (and generously shared in a number of papers in DMPHP, among other venues), obtained at great sacrifice, were invaluable in beginning to understand the infection and develop best practices.

Throughout history, we have never truly prevented or stopped a pandemic. Many unanswered questions about the pandemic influenza, the role of fine particle aerosols, optimal physical and environmental protection, and presymptomatic transmission were never really resolved. ${ }^{6}$ These gaps in our knowledge have now come back to haunt us as we're forced to make decisions based on these questions in the midst of a raging pandemic. We have taken this pandemic so seriously because a newly introduced coronavirus transmitting as a respiratory virus is unprecedented in living memory.

The proverb says that "forewarned is forearmed," and all experts on emerging infectious diseases and pandemics have strongly advocated more effective global surveillance and early warning systems as the first step. ${ }^{7,8}$ Some of the main lessons of this pandemic are that early warning is not enough; political will and leadership, clear and consistent communications based on the best (and often evolving) scientific evidence, and the rapid implementation of public health measures may make the difference between a runaway pandemic and a manageable outbreak. Here, the tenets of our discipline of disaster medicine and public health preparedness clearly apply, even if the scale may be truly global and prolonged.

On a personal note, it has been a privilege to participate in helping the journal to fulfill its mission around the coronavirus pandemic. My heartfelt thanks to the many who made this enormous effort possible. It truly takes a village, and I'm deeply grateful to all who rose so admirably and graciously to the occasion with selfless teamwork, including many who worked on editing manuscripts while they were on the front lines of the COVID-19 response themselves. The Editor-in-Chief, the Deputy and Associate Editors, Managing Editor Alice O'Donnell (volunteers all), and the editors (Andrea Giannini, Julia Musha, and Sara Yanny-Tillar) at Cambridge University Press all worked tirelessly on these manuscripts; I can only guess at the consequences for their own work and families. Reviewers, always pressed for time, unstintingly contributed their expertise. Not least, to the colleagues who submitted manuscripts and shared their experience and insights for the good of the community, a heartfelt thanks.

As summarized by Dr James in an earlier editorial in this journal, history has demonstrated that pandemics have been an inevitable fact of life. ${ }^{9}$ We are paying a high price for our disinvestment in public health, and for the failure to use public health appropriately as the first line of defense. That left disaster medicine and intensive care, normally the last resort, as our only answer to the consequences of a pandemic that should have been largely preventable. We may now have the knowledge and capabilities to change this. The hard won lessons from this experience must not be in vain but should help us to be better prepared for future public health emergencies, whenever they come.

\section{About the Author}

Department of Epidemiology, Columbia University Mailman School of Public Health, New York, New York; Guest editor, Disaster Medicine and Public Health Preparedness.

Correspondence to Stephen Morse, Columbia University Mailman School of Public Health, 722 W. 168th St. Ste. 1504, New York, NY 10032 (e-mail: ssm20@ columbia.edu)

\section{REFERENCES}

1. Longini IM, Nizam A, Xu S, et al. Containing pandemic influenza at the source. Science. 2005;309:1082-1087.

2. Ferguson NM, Cummings DAT, Fraser C, et al. Strategies for mitigating an influenza pandemic. Nature. 2006;442:448-452.

3. Center for Health Security. Event 201. 2019. https://www.centerforhealth security.org/event201/. Accessed October 13, 2020.

4. ProMED-mail, Undiagnosed pneumonia - China (Hubei): request for information (Archive Number: 20191230.68641536). Published December 30, 2019. https://promedmail.org/. Accessed October 13, 2020.

5. Congressional Research Service. COVID-19 and China: a chronology of events (December 2019-January 2020), Report R46354, prepared by Susan V. Lawrence. https://crsreports.congress.gov/product/pdf/R/R46354. Accessed October 13, 2020.

6. Morse SS, Garwin RL, Olsiewski PJ. Next flu pandemic: what to do until the vaccine arrives? Science. 2006;314:929.

7. Morse SS, Woodall JW, Rosenberg BH, et al. ProMED Global monitoring of emerging diseases: design for a demonstration program. Health Policy. 1996;38:135-153.

8. Morse SS. Public health surveillance and infectious disease detection. Biosecur Bioterror. 2012;10(1):6-16.

9. James JJ. "Waiting for Godot" - Epilogue, from pandemic to endemic. Disaster Med Public Health Prep. 2020;epub. doi: 10.1017/dmp.2020.307. 